\title{
MEMORIA E IDENTIDAD
}

\section{Julio De Zan **}

1.

La memoria es elemento constitutivo de la propia identidad. Un sujeto que viviera solamente el presente, o el anhelo de un futuro soñado, sin detenerse a rememorar su pasado, no sabría quién es. La disociación o la negación del propio pasado, que no asume las acciones cometidas, sus consecuencias o las palabras dadas, y, en general, lo ya sido de uno mismo, son maneras de eludir toda responsabilidad y de construirse una falsa inocencia. El niño es inocente porque no tiene pasado ni memoria, pero ya no podemos transformarnos en niños, como pretendía Nietzsche. Mantener viva la memoria de quién hemos sido, de cómo hemos obrado en el pasado y de las promesas que hemos hecho hacia el futuro, es lo primero que se requiere para hacernos cargo de la propia realidad y merecer el respeto de los demás como hombres responsables ante quienes se sabe a qué atenerse porque somos capaces de mantener la palabra empeñada, aun frente a la adversidad. La forma de vida y el carácter del individuo pueden cambiar, porque son contingentes. Lo único que permanece firme y seguro en medio del fluir de las circunstancias y de nuestra propia vida es la identidad moral y la responsabilidad del hombre de palabra. La memoria y la fidelidad a la palabra empeñada son los presupuestos de toda confiabilidad y sociabilidad humana, por lo tanto, la condición de posibilidad de un proyecto común.

Tengo que aclarar enseguida, sin embargo, que la memoria no es, por supuesto, el único componente de la identidad, la cual se integra con la comprensión del presente y el proyecto de lo que queremos llegar a ser, no como una veleidad, sino como la anticipación del futuro en lo que estamos siendo,

* Ponencia enviada como expositor invitado para la Sesión Especial de "Los Maestros de la Filosofía Argentina" en el Congreso Internacional Extraordinario de Filosofía de San Juan (julio de 2007).

** Investigador Principal del CONICET. Profesor Titular en la Universidad Nacional de Entre Ríos y en la Universidad Nacional de General San Martín. Dirección electrónica: jdezan@arnet.com.ar 
o haciendo. Con esto he mencionado las tres dimensiones de la temporalidad, que son en cierto modo inseparables, porque sin memoria del pasado, y sin el plexo de las categorías recibidas de la tradición, no es posible ningún conocimiento comprensivo del presente, $y$ ningún proyecto consistente y realista para el futuro.

La relación de condicionalidad que tienen para nosotros las tres instancias del tiempo se tiene que leer también en la dirección inversa, hacia atrás, porque siempre interpretamos y juzgamos el presente desde los intereses vinculados al proyecto de futuro, y estas dos instancias condicionan, a su vez, la rememoración selectiva que hacemos del pasado. Esta doble vía, que ya había sido pensada por Hegel, es lo que se conoce, desde Heidegger, como el círculo bermenéutico. De los tres momentos de este movimiento circular de doble vía de la existencia me voy a demorar aquí solamente en el primero, que es la memoria.

La circularidad del movimiento existencial de la temporalidad no está determinada por ningún automatismo o ley natural, ni regida por las leyes formales de la lógica, sino que está situada en el terreno de la contingencia y de la facticidad histórica. La memoria es un tesoro de mucha fragilidad, sometido también a la contingencia de la temporalidad y a las deformaciones intencionales, o a las políticas del olvido, como vamos a ver enseguida; y esta fragilidad se traslada de la memoria a la propia identidad del sí mismo que en ella se funda y se mantiene en medio del devenir temporal. ¿Qué significa y cómo es posible entonces permanecer siendo siempre el mismo a través del tiempo, que es la definición del término 'identidad'? Esta pregunta es el hilo conductor del libro más importante de Paul Ricoeur: Sí mismo como un otro ${ }^{1}$, y apunta a la cuestión ontológica de la relación esencial de identidad y universalidad que es constitutiva de la autoconciencia racional propia del hombre $^{2}$. La dinámica de los cambios culturales de las sociedades actuales exige pensar y situar el núcleo de la identidad en el nivel más profundo de la subjetividad moral de la persona, en la identidad intersubjetiva de los

1 Paul Ricoeur, Soi-même comme un autre, Paris, Éditions du Seuil, 1990; Si mismo como otro, México, Siglo XXI, 1996.

${ }^{2}$ Cfr. J. De Zan, "Identidad y universalidad en Paul Ricoeur", en Erasmus, Revista Latinoamericana Interdisciplinaria del ICALA (Intercambio Cultural Alemán Latinoamericano), No 1, Rio Cuarto, 1999, p. 69-84. 
significados lingüísticos y en el mantenimiento de la promesa de la palabra dada, con lo cual la propia identidad se manifiesta como vinculada a la alteridad y abierta a la intersubjetividad universal, como lo ha mostrado el propio Ricoeur en Si mismo como un otro, y se insinúa ya en el extraño título de este libro 3 .

Se oye decir, no sin razón, que el pasado nos divide, que sólo el futuro y el destino común puede reunirnos y reconciliarnos, y esta razón parece contradecir el concepto esbozado en el párrafo anterior. Pero la memoria reconciliada no es olvido, sino rememoración madura y exigencia de justicia que se integra a la economía de las pulsiones, trae su vindicación de justicia del pasado a la situación del presente, y la proyecta hacia un futuro más justo y solidario. El proyecto de justicia provee a la memoria del valor agregado de un compromiso moral y político, que puede y tiene que ser asumido por el conjunto como una promesa de fidelidad inquebrantable que nos hacemos. En tal sentido no se puede sino ponderar el acierto del título emblemático, Nunca más, elegido por los autores del libro fundamental de la memoria trágica de los años '70 en Argentina, el cual perdura más allá de las críticas al enfoque de esta historia, sobre la cual volveremos un poco más adelante.

En el capítulo 1 de la Parte II de la Genealogía de la Moral dice Nietzsche que el hombre se puede definir como "el animal que es capaz de hacer promesas, y mantenerlas en el tiempo". El mantenimiento de las promesas es el núcleo duro de la memoria y de la identidad del sujeto. Pero enseguida agrega este autor que "la fuerza que actúa en contra de la memoria es la capacidad de olvido"4. El olvido no es considerado aquí en el sentido trivial de la incapacidad de recordar algo (embarazosa experiencia de los sexagenarios), sino como una fuerza activa y positiva que es capaz de silenciar los reclamos del pasado, de abrir en la conciencia el espacio para lo nuevo, y sobre todo "para las acciones más nobles del crear, el proyectar, el gobernar". El olvido es la capacidad inhibitoria que impide el persistente retorno del pasado y su dominio sobre el presente. Sin un adecuado funcionamiento de este aparato inhibitorio quedaríamos como atragantados

${ }^{3}$ P. Ricoeur, op. cit., p. 112.

${ }^{4}$ Friedrich Nietzsche, La genealogia de la moral, Madrid, Alianza, 1972, p. 65. 
y paralizados por la incapacidad de digerir y asimilar el pasado. Seríamos eternos rumiantes. El hombre activo y enérgico es también "ese animal olvidadizo", que es capaz de descargar soberanamente su memoria de las ofensas, las quejas y las malas ataduras del pasado que lo tiran hacia atrás y le cierran el futuro. "Con lo cual -concluye Nietzsche- resulta claro que sin capacidad de olvido no puede haber ninguna felicidad, ninguna jovialidad, ninguna esperanza, ningún orgullo, ningún presente"s. En otros términos, ligados al psicoanálisis: "La elaboración no implica la integración o transformación del trauma del pasado en una memoria narrativa sin suturas [...] en el mejor de los casos, la narrativa no ayuda a cambiar el pasado a través de una dudosa reescritura de la historia, sino a elaborarlo de una manera que abra futuros posibles [...] La elaboración contrarresta la tendencia a -sacralizar el trauma [...] que provoca una avasallante, y hasta incapacitante sensación de traición si nos apartamos de la fidelidad que le debemos, o les debemos a quienes fueron destruidos por los acontecimientos relacionados con el trauma"6.

Es preciso decir entonces, con Nietzsche, que la memoria es ambivalente: el exceso de memoria mata. En este juego de memoria y olvido hay que situar el origen y el problema de la responsabilidad, escribe también Nietzsche al comienzo del capítulo 2 del citado libro. La responsabilidad no se vincula solamente a la memoria, sino también al olvido. Porque la conciencia de culpa, y el encono por los agravios de todo el pasado es una carga abrumadora, o aplastante, que hay que digerir, o asimilar, y bloquear su retorno por medio del aparato inhibitorio del olvido. La responsabilidad seria y posible se avoca al presente y se dirige al futuro. En un bello elogio de la responsabilidad, dice Nietzsche que "solamente el hombre que sabe olvidar puede realmente hacer promesas, porque es señor soberano de su voluntad, y es capaz de inspirar confianza", porque no está dominado por el resentimiento. La fijación de la mirada acusadora en algún momento traumático del pasado deja encadenado al otro (y a nosotros mismos) a ese pasado, le quita o le niega su presente y todo horizonte de futuro. Esta situación, en la que hemos quedado como petrificados en el pasado, y ya no

${ }^{5}$ Ibid., p. 66.

${ }^{6}$ D. LaCapra, Historia en tránsito. Experiencia, identidad, teoría crítica, Buenos Aires, Fondo de Cultura Económica, 2006, pp. 167 y 169. 
tenemos más presente ni futuro, es precisamente la definición sartreana de la muerte. El que es objeto de de esta operación objetivante de la memoria obsesiva de los otros queda como congelado en un tiempo que querría olvidar, o que podría reparar en el presente mediante acciones orientadas a saldar sus deudas. Pero la mirada acusadora del otro lo paraliza. Esta memoria es excluyente en un sentido especial. Sólo resta de él aquella forma petrificada o cadavérica de un negro pasado. No es más que un muerto vivo, condenado a habitar en el espacio muerto de la cercanía de los sepulcros, hasta que se convierta en un muerto muerto y reciba su lápida. Lo que no saben los sepultureros es que la obsesión de la memoria los ata también a ellos al mismo pasado, les hace perder la capacidad de vivir creativamente el presente y proyectar un futuro diferente.

2.

Para avanzar en nuestro tema tengo que introducir ahora una diferencia fundamental entre lo que yo llamaría la memoria de la responsabilidad, y la responsabilidad de la memoria. El cultivo de la primera, la memoria de la responsabilidad, es la virtud que redime al criminal, o a los culpables de alguna manera, que somos todos. Hacernos cargo de las deudas contraídas con los demás es el principio de la reparación y de la reconciliación, que no significan el olvido, porque lo sido, el pasado de nuestro ser, es la parte de nosotros mismos que no se puede ya cambiar ni hacer desaparecer, sino que hay que cargar siempre con ella. Lo que hay que construir es la reconciliación de la memoria, o en la memoria y la verdad, en el juramento del nunca más y el olvido de los odios, del deseo de venganza y el resentimiento que hacen imposible todo proyecto común. Para explicar el otro lado de esta unidad de memoria y responsabilidad, podemos recurrir a un concepto weberiano, y hablar aquí de la ética de la responsabilidad en el uso de la memoria. Esta es la virtud de los vencidos, y de las víctimas, sin la cual no es posible cerrar las heridas del pasado, resolver los conflictos de la memoria y abrir la posibilidad del futuro. Tzvetan Todorov se refiere, entre los abusos de la memoria, a las prácticas que llevan a instituir y a perpetuar el estatuto 
de la víctima, y el rol de acreedores de una deuda que no se puede saldar ${ }^{7}$. El ejercicio responsable de la memoria impone límites prudenciales a los reclamos, para no hacer pesar sobre la sociedad de tal manera los conflictos y las culpas del pasado que se comprometa la construcción solidaria del futuro.

En este punto me voy a remitir a uno de los últimos libros publicado antes de su muerte por el mencionado filósofo francés Paul Ricoeur, el cual lleva como título: La memoria, la historia, el olvido. En el prólogo de esta extensa obra confesaba el autor que su investigación sobre este tema era el fruto de su preocupación sobre una situación observable en los espacios públicos: "Estoy perplejo, escribe, por el inquietante espectáculo que dan el exceso de memoria en algunos espacios y sobre determinados acontecimientos, y el exceso de olvido en otros casos, por no hablar de las influencias de las conmemoraciones y de los abusos de memoria -y de olvido. En este sentido, la idea de la justa memoria es uno de los temas centrales de mi preocupación cívica"8. La preocupación cívica de Ricoeur como ciudadano francés y de la Comunidad Europea no puede menos que despertar un especial interés para nuestra propia preocupación por la situación de la sociedad argentina y de otros países de América Latina, en los cuales las cuestiones de la memoria que intenta clarificar Ricoeur con sus análisis y reflexiones son también de una grave conflictividad, y de una significación fundamental para nosotros.

La reflexión sobre las tragedias históricas del siglo $\mathrm{XX}$, sobre la experiencia de los traumas aún no resueltos, sobre los síntomas postraumáticos y el revival de la memoria traumática de los grupos humanos es uno de los ejes centrales del pensamiento filosófico, de los estudios históricos y de la literatura actual del mundo occidental, y esta cuestión ha llegado a generar un campo disciplinario especial y se ha convertido en una preocupación central de ciertas áreas de las ciencias sociales ${ }^{9}$. También cabe aludir a la reacción adversa contra esta proliferación de los "estudios del

7 T. Todorov, Les Abus de la mémoire, Paris, Arlea, 1995; traducción española: Los abusos de la memoria, Barcelona, Paidós, 2000.

8 P. Ricoeur, La mémoire, l'bistoire, l'oubli, Paris, Éditions du Seuil, 2003; traducción española: La memoria, la historia, el olvido, Madrid, Trotta, 2003, p. 13.

${ }^{9}$ Cfr. D. LaCapra, op. cit., pp. 147 y ss., con abundante bibliografía internacional. 
trauma" y la tendencia a ocupar un lugar central en las ciencias sociales. El citado estudio de LaCapra y sus confrontaciones críticas con diferentes puntos de vista permite reconstruir el estado de situación de los ensayos sobre el tema, pero se concentra especialmente en el problema de cómo escribir críticamente esta historia, y en el análisis de los fenómenos psicológicos ligados a las experiencias de estas tragedias humanas. Estos aportes son relevantes y significativos para nuestra propia preocupación ético-política, para la formación del juicio crítico sobre la experiencia y la memoria de los años 60/70 en la Argentina, y para la tesis de más amplio alcance que intenta sostener este artículo.

El tratamiento sistemático de la cuestión de la memoria exige marcar también la diferencia entre la memoria viva y la bistoria escrita, o la historiografía. Estas son cosas bien diferentes y mantienen entre sí una relación ambigua, a la que solamente podemos aludir aquí. Por un lado, los primeros historiadores, como Heródoto, dicen que escriben la historia para mantener la memoria de los acontecimientos del pasado y evitar que el paso del tiempo los suma en el olvido. Pero, por otro lado, la historia escrita puede superponerse y reemplazar o alienar la memoria propia y el relato de los sobrevivientes. La memoria viva tiene sus fuentes en la experiencia de los acontecimientos y en la tradición oral, pero en tanto la distancia temporal va cegando estas fuentes es reemplazada por la historiografía. El ensayo de Nietszche sobre La utilidad y los inconvenientes de la historia para la vida, debería recomendarse especialmente hoy contra la avidez por la lectura de libros de historia, sobre todo local, que está muy de moda, la cual puede ser expresión del impulso, tan argentino, de mirarnos el ombligo, pero conlleva también la creencia, denunciada por Nietzsche, de que es necesario mirar al pasado para comprender el presente. Tales lectores de literatura histórica se engañan, porque los que escriben estas historias proceden de hecho a la inversa, inevitablemente construyen el relato del pasado desde una perspectiva del presente, que es la suya propia. Si no quiere pecar de ingenuidad el lector tiene que preguntarse primero por lo tanto dónde está parado el autor de la historia que va a leer, para qué proyecto trabaja él, y cuál es el tipo de historia que escribe, teniendo en cuenta la tipología de Nietzsche, o alguna otra. Pero aquí no nos interesa la epistemología de la historia, sino la experiencia de la memoria. 
En el texto siguiente, Dominick LaCapra plantea en versión condensada su manera de comprender esta relación:

\begin{abstract}
Dado que la memoria es parte importante de la experiencia, el problema de la relación entre historia y memoria es una versión abreviada del problema de la relación entre historia y experiencia. Reiteraré aquí el postulado que desarrollo in extenso en el primer capítulo de History and Memory after Auschwitz (1998). Historia y memoria no deberían oponerse de manera binaria, ni tampoco fundirse, o confundirse. Sus relaciones son complejas $[. .$.$] Cuando trata cuestiones de la memoria, incluyendo,$ por supuesto, las cuestiones del olvido, de la represión o la elusión [...] la historiografía puede aportar a la esfera pública una memoria críticamente testeada y veraz, que los distintos grupos que conforman la sociedad internalizan como pasado recordado. En cualquier caso, la memoria como parte de la experiencia de un grupo está ligada a la manera como ese grupo se relaciona con su pasado, en tanto éste influye sobre su presente y su futuro ${ }^{10}$.
\end{abstract}

Cuando la historia no es mera crónica académica de los hechos del pasado, explora los testimonios de la experiencia y la memoria como algo más que el mero acontecimiento, y que tiene que ver con la autocomprensión de los sujetos sociales. Más adelante aclara el autor otros aspectos relevantes de esta diferencia entre los acontecimientos, o los hechos históricos y la experiencia traumática de los mismos, en un sentido que podemos llamar hermenéutico:

la experiencia, en contraste con el acontecimiento, no se puede localizar, o fechar, y es un pasado que no pasará: un pasado [que permanece, o retorna], que tardiamente invade el presente y amenaza con bloquear el futuro [...] La experiencia del trauma puede ser vicaria, o virtual, es decir, padecida de manera secundaria por alguien que no estuvo allí, o no pasó por los acontecimientos traumatizantes propiamente dichos. En la experiencia vicaria del trauma, el sujeto se identifica inconscientemente con la víctima, transformándose en víctima sustituta y viviendo el acontecimiento de manera imaginaria.

${ }^{10}$ Ibid., p. 97. 
En otro lugar se menciona el ejemplo, real o imaginario, de una identificación del creyente tan intensa con los padecimientos de Cristo que, sin haber sido crucificado, recibe en sus propias manos el estigma de las llagas.

En la experiencia virtual del trauma (a diferencia de la vicaria) el sujeto se coloca imaginariamente en el lugar de la víctima respetando la diferencia entre el yo y el otro, y reconociendo que no puede ocupar el lugar de la víctima, ni tampoco hablar con su voz. [...] Juzgar si esta posible traumatización secundaria es o no deseable, entrañaría considerar cómo funcionan [en el caso] las cuestiones éticas, políticas y sociales $[\ldots]$ o religiosas ${ }^{11}$.

Una forma de escribir historia, que se conecta estrechamente con la memoria viva, es la que ha practicado Pierre Nora en su investigación sobre la memoria12. "Lo novedoso de esta manera de escribir historia -comenta el autor- es que rompe con el hábito cronológico. Partimos del presente para hacer un inventario de aquellos objetos, hombres o lugares que pertenecen a la memoria colectiva". En la historia se producen quiebres y rupturas más o menos profundos, que hacen que los acontecimientos y las épocas del pasado pierdan toda significación para comprender el presente y ya no formen parte de la memoria viva de los pueblos; estos sujetos colectivos también cambian radicalmente a lo largo del tiempo, de manera que tampoco pueden experimentar aquella historia como propia, a no ser de modo imaginativo y virtual, y solamente pueden tener con ese pasado la relación objetivante del observador externo. Hay que tener en cuenta, sin embargo, que la memoria traumática, como piensa LaCapra, "al menos según Freud, implica [muchas veces] una temporalidad demorada o tardía y un período de latencia". P. Nora pone de relieve también éste y otros aspectos:

11 Ibid., pp. 171-173 y 176.

12 P. Nora, Les lieux de mémoire, 3 vols, Paris, Gallimard, 1984-1993. 
La memoria es el recuerdo de un pasado vivido, o imaginado [...] por naturaleza es afectiva, emotiva, abierta a todas las transformaciones, vulnerable a toda manipulación, susceptible de permanecer latente durante largos períodos y de bruscos despertares. La memoria es siempre un fenómeno colectivo, aunque sea psicológicamente vivida de manera individual. Por el contrario, la historia es una construcción siempre problemática e incompleta de aquello que ha dejado de existir, pero dejó rastros [...] es una operación puramente intelectual, laica, que exige un análisis y un discurso crítico [...] El ejemplo francés es muy interesante. La historia oficial cumplió un papel capital, porque consiguió reprimir las memorias, limitarlas al seno de las familias, al ejercicio privado. Un niño podía ser hijo o nieto de un aristócrata asesinado en la Revolución, hijo de un obrero asesinado en la Comuna, judío emancipado desde hacía poco, inmigrante o bretón. Pero cuando estaba en la escuela era un pequeño francés como cualquier otro que recitaba nuestros ancestros, los galos. Lo que sucedió en los últimos 40 años es que se rompió ese doble registro privado/público, y que esas memorias particulares de las minorías reclaman ser como las demás, reconocidas por la mayoría nacional y, a la vez, conservar algo de sus identidades, lo que llaman su memoria [...] El sujeto nacional portador de la ideología de la nación está en grave crisis. La guerra, los genocidios, los totalitarismos han dejado una memoria muy fuerte $y$ fragmentada. Pensemos en la Segunda Guerra Mundial y en el gobierno colaboracionista de Vichy. Francia salió de esta experiencia trágicamente dividida: había una memoria de la resistencia, una memoria de los racistas, una memoria de los colaboracionistas y otra de los prisioneros [...] Entonces en las escuelas comenzó a ser muy difícil transmitir una memoria oficial ${ }^{13}$.

Volveré más adelante sobre este problema.

3.

El uso de la memoria puede verse impedido en el individuo por diferentes patologías psíquicas. Quiero evocar todavía, siguiendo a Ricoeur, estos fenómenos psicológicos, porque ayudan a comprender las patologías

13 Pierre Nora, entrevista de Luisa Corradi, en La Nación, Buenos Aires, miércoles 15 de marzo de 2006. 
sociales del uso de la memoria. Freud estudió los obstáculos principales en el camino de la rememoración: los recuerdos traumáticos que no podemos asimilar, como la muerte de un ser querido, y mostró cómo opera el duelo en la aceptación de lo irreparable y en el reconocimiento de que el objeto de nuestro amor ha dejado de existir y solamente podemos recuperarlo y llevarlo en el recuerdo.

Si bien la interpretación meramente psicológica de la historia es reductiva, y pierde lo esencial, en un sentido por lo menos analógico se puede hablar también de traumatismos colectivos de la memoria, o de una memoria colectiva herida. Pero esta transposición de categorías propias de las patologías psíquicas de la memoria adquiere una significación mayor en tanto se la puede vincular a esa constante estructural de la historia y de la existencia política, que son los efectos de la violencia. La formación de los grandes Estados nacionales de la modernidad, tanto en Europa como en las Américas, para evocar la historia más conocida para nosotros, ha sido el resultado de largas y sangrientas guerras civiles y entre las naciones. Ricoeur evoca el relato hobbesiano sobre la constitución de la sociedad y del orden jurídico-político a partir del estado originario de guerra permanente y del miedo a la muerte violenta, y considera que éste es un relato verídico incluso si se lo quiere leer como una generalización histórica, porque "no existe ciertamente comunidad histórica que no haya nacido de una relación que se puede asimilar a una guerra de algún tipo. Lo que celebramos con el nombre de acontecimientos fundadores son esencialmente actos violentos legitimados después por la institución de un estado de derecho, el cual es, sin embargo, siempre precario" 14 .

En los rituales festivos de las conmemoraciones patrióticas, el lado violento y el punto de vista de los vencidos, o de las víctimas, se halla como difuminado u oculto bajo la nueva piel que ha recubierto las heridas suturadas del pasado. La pacificación interna y la estabilidad de las instituciones ha sido la obra del olvido de los conflictos y los odios anteriores. Pero este trasfondo subterráneo de la memoria ha sido excavado recientemente por la teoría crítica de la historia. "En los últimos tiempos la memoria se ha vuelto un tema candente entre los historiadores, y a menudo

${ }^{14}$ P. Ricouer, La memoria, la bistoria, el olvido, ed. cit., p. 109. 
produce más calor que luz. Los debates sobre la memoria son esquirlas de las guerras culturales, y cuando se menciona la memoria, la identidad y las políticas de identidad nunca están lejos"15.

La política cultural de las élites dominantes, constructoras de los grandes Estados modernos, en ambos lados del Atlántico, ha sido fundamentalmente una política de universalización, o de imposición de la memoria de los vencedores, de la borradura de sus propios crímenes, del olvido del sufrimiento de los vencidos, y de la violencia de toda esta historia. Puede hablarse de una estrategia de manipulación de la memoria mediante el potente instrumento de la historia escrita por los vencedores. La consolidación de los Estados modernos ha pretendido legitimarse casi siempre mediante políticas culturales orientadas a la construcción de nuevas identidades nacionales integradas y homogéneas, llevadas a cabo especialmente desde el siglo XIX a través del sistema educativo y de la conscripción militar, que han consumado el olvido de la memoria propia de las víctimas y de los grupos dominados, y han inducido su identificación con la cultura y con la política de las clases dominantes.

En la época actual la política de la memoria en la Argentina ha consistido en oficializar la memoria de las víctimas del terrorismo de Estado, y en la apropiación de la gestión de esa memoria por este mismo Estado. Esta pseudo-identificación del Estado con sus víctimas es una parodia que no debería se aceptada por la sociedad civil, porque el Estado es el victimario, el verdugo. Digo que lo es y no que lo fue porque, aunque en la actualidad no cometa el mismo tipo de violaciones de los Derechos Humanos, es el mismo Estado, tiene continuidad jurídico-institucional con aquel Estado terrorista y, así como se ha hecho cargo de la deuda externa contraída por gobiernos anteriores, tiene que hacerse cargo de esta deuda interna impagable. Por lo tanto, la actitud que debe exigirse de los funcionarios que hablan y actúan desde el Estado, es el arrepentimiento, el pedido de perdón y la reparación de lo irreparable mediante la Justicia.

La intervención del Estado en la construcción de esta memoria comenzó muy temprano, con la integración de la CONADEP y con el producto de esa comisión oficial: "El Nunca más instaló en la escena pública

${ }^{15}$ D. LaCapra, op. cit. p. 96. 
una nueva 'memoria emblemática', una lectura fundacional sobre la violencia política y las desapariciones" a partir de la recopilación de testimonios de la víctimas sobrevivientes y de los familiares de los desaparecidos. Pero "integró la narrativa humanitaria forjada durante la dictadura para denunciar estos crímenes con los postulados del Poder Ejecutivo para pensar este pasado"16. Estos postulados apuntaban a una despolitización de la memoria, y establecían la restricción de los puntos de vista sobre el pasado, limitadas al aspecto moral y jurídico de la violación de los derechos humanos, porque el relato de los hechos debía servir como prueba objetiva para el juicio a las Juntas Militares. Conforme a los requerimientos jurídicos, el juez no puede estar involucrado de ninguna manera directa o indirecta en los hechos, y en caso contrario debe inhibirse de juzgar. Los miembros de la CONADEP, que actuaban en representación de toda la sociedad argentina, presuponen consecuentemente un sujeto, "un nosotros inocente al ejercicio de la violencia y del terror del Estado, una comunidad de ciudadanos ajenos a los enfrentamientos políticos que signaron a la sociedad argentina". Este punto de vista se extiende a los guerrilleros y militantes políticos. Resulta llamativo que el relato del Nunca más "se limita a hacer públicos los nombres de los secuestrados, torturados y desaparecidos, los describe como 'personas o seres humanos', y sólo en el 3\% de los casos menciona su condición de militantes"17. Esta perspectiva del relato conlleva una doble operación: por un lado restituye la humanidad a los desaparecidos como sujetos de derechos que han sido violados, y al mismo tiempo despolitiza su personalidad al describirlos como víctimas inocentes.

Desde mediados de los ' 90 se reavivó la memoria sobre ese pasado y adquirió un significado independiente de la meta punitiva del '83, y más orientada a la trasmisión de aquella memoria a las nuevas generaciones mediante la constitución de archivos, museos, inscripciones recordatorias, libros y textos escolares, conmemoraciones, nuevas organizaciones de familiares, etc. En este nuevo contexto el Nunca más, que había jugado un papel fundamental en la construcción de la memoria de la víctimas de la dictadura militar, volvió a reeditarse, pero también fue objeto de múltiples discusiones por el nivel de abstracción y despolitización de su relato. Estos

${ }^{16}$ Emilio Crenzel, La bistoria política del 'Nunca más", Buenos Aires, Siglo XXI, 2008. 17 Ibid., pp.107 y 109. 
debates son en principio necesarios para integrar una memoria más concreta y cercana a la realidad histórica del pasado, con sus luces y sombras. Pero la repolitización de esta memoria ha cobrado sesgos diferentes en la relectura de los diversos sectores políticos que han tratado de apropiarse de ella y de usar la potencia de su significado simbólico en función de los intereses partidarios o de grupos. Estos malos usos de la memoria no han sido practicados solamente por el Estado y los políticos, sino también por algunas de las propias organizaciones de los derechos humanos y de los familiares de las víctimas.

En la medida en que la memoria se fracture, y se reabra el conflicto de las interpretaciones, ingresamos nuevamente en un camino que conduce al retorno absurdo de los conflictos y de las luchas a muerte del pasado. La distancia histórica permite sin embargo construir un nuevo relato que integre los retazos de la memoria verídica de todos los sectores, y que reconozca que, si bien es cierto que los que emplearon la fuerza pública del Estado en procedimientos ilegales de violaciones atroces de los derechos humanos, cargan con una culpabilidad especialmente agravada, que no se puede diluir ni equiparar con ninguna otra, también es cierto que en aquella historia del horror nadie fue enteramente inocente.

4.

Quiero volver ahora al enunciado con el cual había comenzado, sobre "la memoria como constitutiva de la identidad", para reflexionar sobre esta relación en el plano de la memoria y las identidades sociales colectivas, las cuales son también temporales e inestables. La reproducción y la duración de las identidades políticas de la modernidad dependen de la institución Estatal que las ha creado. Las políticas de identidad que los Estados nacionales aplicaron sistemáticamente durante el siglo XIX a través de la historia escolar impartida por el sistema educativo oficial centralizado llevaron a cabo eficazmente un proceso de aculturación de la diversidad cultural preexistente en sus vastos territorios, destinado a consolidar la unidad nacional y la legitimación del sistema de la dominación estatal. Pero en la medida en que el Estado ha ido perdiendo la centralidad en la vida social y cultural, los rituales de la memoria por él administrados han visto erosionada su fuerza modeladora de identidad. La historiografía crítica ha 
disuelto el aura de los héroes y, como alguien ha escrito, hoy no hay nada más invisible en nuestras ciudades que sus grandes monumentos. La rememoración de aquel lejano pasado ha quedado como un juego de niños en los patios escolares. La presencia de los padres en las fiestas patrias no está motivada por el propio deseo de la conmemoración del pasado, sino por la demanda de los niños para festejar su representación, que es lo único que vale por sí mismo en estos actos patrios, independientemente de lo representado. Esto no quiere decir que carezcamos de identidad, sino simplemente que vivimos en tiempos de transición, en los que se están gestando nuevas identidades.

El español Mario Carretero ha estudiado el papel de la enseñanza de la historia en la construcción de las identidades nacionales en diversos países, los problemas con que se enfrentan en el mundo actual las prácticas tradicionales en este campo y los debates de los historiadores sobre qué hacer con la historia en la Escuela frente a la crisis de aquellas identidades ${ }^{18}$. La investigación de este autor parte de una clarificación de la diferencia de tres representaciones del pasado que se orientan por objetivos muy distintos, y que actúan de manera diferente, y en muchos casos conflictiva, en la experiencia social. En primer lugar, el registro de la historia como trasposición didáctica orientada a la formación cívica y ciudadana que se imparte en los programas oficiales de la escuela. En segundo lugar, la historia académica, o la historiografía, que escriben los historiadores y los cientistas sociales de acuerdo con la lógica de la investigación y de la validación de las interpretaciones o reconstrucciones del pasado que es propia de estas ciencias. Por último, tenemos la historia vivida, como elemento de una memoria colectiva que se inscribe de maneras diferentes en la mente y en los cuerpos de los miembros de cada sociedad, según los lugares en los que están situados los grupos y los individuos dentro de esta sociedad, y sus respectivas posiciones en los conflictos sociales. A esta memoria propiamente dicha, que no se alimenta solamente de la ciencia de la historia, sino de la propia experiencia, me voy a referir en los puntos siguientes.

18 M. Carretero, Documentos de identidad. La construcción de la memoria histórica en un mundo global, Buenos Aires, Paidós, 2007. 
Las historia como disciplina de las ciencias sociales, que busca el conocimiento científico del pasado, pretende un conocimiento objetivo y crítico de los hechos y su incorporación en la currícula escolar, debería tener como objetivo fundamental el desarrollo de las habilidades cognitivas en este campo. Lo que se enseña en la escuela, en cambio, bajo el nombre de bistoria, es un relato construido con la finalidad de formar una identidad colectiva, en el que predomina la dimensión afectiva, que promueve la identificación con el proyecto de los fundadores de la nacionalidad, conforme al paradigma romántico. "Es, por eso un relato narcisista, destinado a producir adhesión emocional a lo nuestro [...] a nuestra nación legitimadora de nuestro Estado, que es por cierto el patrón de la escuela"19. Como escribe Carretero, la fuerza de las motivaciones románticas, que apela a las emociones, tienen una notable y probada ventaja como fuerza modeladora de la identidad y la autoconciencia nacional mediante su influencia sobre la autocomprensión y el orgullo colectivo, y por lo general prevalece sobre cualquier otro objetivo, incluidos los objetivos cognitivos de la historiografía crítica.

El citado autor se sorprende de que todo ciudadano de países como Argentina, Bolivia, Chile, etc., considere natural que exista tempranamente en la escuela un juramento a la bandera, o celebraciones de las fechas patrias. Incluso que estas fiestas sean las que vertebran el calendario escolar como eje de la rememoración del pasado y del tiempo en general, también del presente del año escolar.

En países europeos, como España, sorprendería enormemente la posible incorporación de símbolos patrios en la escuela. Para los ojos europeos, las actividades histórico-patrióticas, que son parte de la esencia de los sistemas escolares iberoamericanos -también de los EEUU y de otras naciones [como las del mundo islámico]- son consideradas más cercanas al adoctrinamiento que a la enseñanza disciplinaria de la historia [...] Considerando su papel en los procesos de formación de las identidades nacionales, y eventualmente su posible relación, en casos extremos, pero no infrecuentes, con la producción de

${ }^{19} \mathrm{~J}$. Ávarez Junco, en el prólogo al libro citado en la nota anterior. 
lo que Maalouf denomina identidades asesinas ${ }^{20}$, las versiones escolares parecen articular, por un lado, una construcción de narraciones sobre la base de un relato único, que funciona como un implante de recuerdos, más que como una memoria, $y$, por otro lado, las versiones escolares de la historia articulan una experiencia [producida performativamente por ellas mismas en el recinto de la escuela], que da forma a una peculiar memoria emocional, cargada de identificaciones y arrullada al ritmo de inflamados himnos, en lo que podemos caracterizar como performances patrióticas $^{21}$.

Cabe preguntarse, entonces, cómo es posible que la historia haya continuado asumiendo esa función contraria tanto a las pretensiones de validez objetiva universal de la propia historia en cuanto ciencia social como a las orientaciones críticas sostenidas por el discurso pedagógico desde hace tiempo. Parece que la respuesta a esta pregunta hay que buscarla en la política, como una exigencia que el poder central plantea a la escuela, porque la cuestión de la identidad, violando la autonomía más profunda del sujeto, ha seguido siendo una política de Estado. Estas contradicciones y especialmente la contradicción de las políticas homogeneizadoras de la identidad con los principios constitutivos de una democracia pluralista, han dado lugar a intensos debates en diversos países en las últimas décadas, entre los historiadores, los profesores de historia, y los pedagogos.

5.

En los comienzos del siglo XXI experimentamos que las políticas de la memoria y del olvido del siglo XIX ya no funcionan con respecto a las nuevas heridas que la memoria viva arrastra del siglo $\mathrm{XX}$, uno de los más crueles y atroces de la historia occidental. La reconciliación mediante aquel tipo de elaboraciones no es posible, entre otros motivos, porque el presunto artífice de la pacificación y guardián de los derechos ha sido ahora el

20 A. Maalouf, Les identités meurtrières, Paris, Grasset \& Fasquelle, 1998; traducción castellana: Las identidades asesinas, Madrid, Alianza, 1999. Cfr. también, del mismo autor: Les croisades vues par les Arabes, Paris, Lattes, 1998; traducción castellana: Las cruzadas vistas por los árabes, Madrid, Alianza, 2006.

${ }^{21}$ M. Carretero, op cit., pp. 23-24. 
principal responsable de los crímenes, y porque las pérdidas no han sido el precio de una conquista de la libertad, o de la institución de un nuevo derecho más justo y solidario, sino las víctimas de meros genocidios administrativos de Estados totalitarios, de la violencia como método, ejecutada por absurdos terrorismos de uno y otro lado, del secuestro y desaparición de miles de ciudadanos, de la perpetuación de las desigualdades y de las relaciones de dominación y de exclusión.

La desaparición de personas elimina toda posibilidad del relato de una muerte heroica y cubre a las víctimas con un manto de anonimato e incertidumbre sobre su destino final. Se intentó hacer desaparecer los restos de los desaparecidos, borrar los rastros de su existencia, enterrados como $\mathrm{NN}$ o en lugares ocultos, sin ninguna identificación, arrojados al mar o incinerados. Se intentó con esto borrar toda posibilidad de recuperar la memoria. Sin embargo, esta estrategia ha producido lo contrario del olvido que se proponía lograr. Porque la desaparición de los restos dejó viva por mucho tiempo la esperanza de encontrarlos con vida y la búsqueda desesperada de los familiares y amigos que no podían resignarse a lo peor. Esta búsqueda no se detuvo cuando aquella esperanza se fue apagando, sino que se ha prolongado indefinidamente impulsada por la necesidad de identificar los restos para elaborar el duelo y cerrar la historia de las biografías inconclusas de los seres queridos.

Estos recuerdos traumáticos de la memoria colectiva, como el de las víctimas de la dictadura militar en Argentina y otros países de América Latina, requieren una elaboración enteramente diferente a la de la muerte en combate de los héroes del más remoto pasado, la cual se encuentra en estado avanzado en nuestra sociedad, y puede transformar la memoria en proyecto colectivo de lucha por el reconocimiento del valor moral de la persona como fin en sí mismo, de sus derechos inalienables cualquiera sea su ideología, y de compromiso político por la realización positiva de los derechos y los valores fundamentales que han sido violados en el pasado reciente. Pero los sujetos principales de esta nueva historia de sublimación de las heridas de la memoria no pueden ser ahora los sectores dominantes y los Estados, sino los vencidos, o las víctimas de la violencia política. La memoria viva de estos sujetos es la fuente a partir de la cual se construye la nueva identidad colectiva de las sociedades actuales, en la medida en la que todos los 
ciudadanos comienzan a sentirse co-responsables de los acontecimientos que han tenido lugar en un pasado reciente en la sociedad y en el Estado de su pertenencia, así como de la violencia estructural, de la pobreza y la exclusión social que persisten en el presente, y en que todos los ciudadanos hacen suyo el sufrimiento de las víctimas y su clamor de justicia. Esta es ya la nueva identidad que puede unirnos a todos sin distinción.

El lugar social de este nuevo acontecimiento político de la memoria no son los espacios estructurados de las instituciones estatales, sino los espacios públicos autónomos, dinámicos y no institucionalizados de la sociedad civil. El Estado podrá y tendrá que acompañar este proceso, pero no puede pretender protagonizarlo ni manipularlo. Los ritos de la conmemoración y los símbolos de la nueva memoria viva que se está construyendo tienen que ser muy diferentes. Las sociedades están inventando nuevos símbolos, y un tipo distinto de evocaciones recordatorias, que no pueden ser los mármoles monumentales levantados sobre grandes pedestales (como las estatuas de los héroes) porque, como alguien ha escrito, no se pueden levantar monumentos a la propia vergüenza. Las preguntas son entonces: “¿cómo inscribir las huellas del sentimiento en la superficie dura de la ciudad? [...] ¿Cómo aunar el cuidado de los sobrevivientes y el respeto a los muertos con un compromiso alerta hacia vivos" y hacia las nuevas generaciones?22 La memoria viva que tenemos en común ya no es la de la glorias de antiguas batallas victoriosas, ni el culto de grandes héroes nacionales, sino la memoria de los crímenes y del sufrimiento de las víctimas, de los anti-héroes del horror y de las políticas de exclusión. (Los "héroes de Malvinas" fueron también víctimas, utilizadas por los mandos militares, juntamente con la causa de la soberanía de las Islas australes, como instrumentos de una desesperada y fracasada operación cuyo fin era la consolidación de la dictadura militar; víctimas y vencidos de una guerra desigual, enviados como carne de cañón a una derrota previsible, y víctimas del abandono del Estado después de la derrota).

22 Cfr. Ibero-Amerikanisches Institut (ed.), "Escribir el recuerdo en el cemento. Monumentos, parques y prácticas de la memoria en Buenos Aires y Berlín", BerlinBuenos Aires/Buenos Aires-Berlin, Berlin, Hans Schiller Verlag, 2004. Cfr. También, La cultura berida. $A 30$ años del golpe militar, Revista $\tilde{N}$ de Clarín, $\mathrm{N}^{\circ} 129$, con bibliografía. 
6.

La cuestión seria de la memoria viva, que ha marcado a fuego la identidad actual de los ciudadanos adultos, no está ligada ya naturalmente a la historiografía de los acontecimientos fundacionales del Estado nación en el pasado remoto, que solamente se reconstruye de manera artificial mediante la política oficial de fastuosas conmemoraciones, sino que está ligada a otros acontecimientos trágicos de la historia reciente de la sociedad en que vivimos, cuyo relato se elude por lo general en la escuela, y ocupa un lugar incipiente en la historiografía, dado que la escasa distancia histórica hace difícil la interpretación objetiva de los mismos. Jürgen Habermas habla de "identidades posnacionales", y esta expresión me parece adecuada, porque en nombre de las identidades nacionales particulares se han llevado a cabo, después de las guerras de la independencia, sangrientas guerras civiles y entre países vecinos, opresión de las minorías, genocidios de los pueblos originarios, etc., y porque situados en el lugar de las víctimas comprobamos que también otras historias y otras experiencias contemporáneas en lugares diferentes han dejado heridas profundas en la memoria de las sociedades y fuertes compromisos morales con la justicia, los derechos humanos y los valores o principios morales en los que se fundamentan. Se trata de principios cuya validez es universal, independiente de las historias y las experiencias particulares en cuyos contextos fueron redescubiertos $y$ valorados como fundamentales, y que inspiran movimientos trasnacionales o cosmopolitas comprometidos en su defensa.

Desde las décadas finales del siglo XX, es la memoria viva de las grandes tragedias la que ha redefinido las identidades tradicionales de las naciones europeas. Esto es especialmente visible, aunque de manera distinta y con ritmos muy diferentes, en los casos de Alemania y de España. "La Guerra civil Española puede considerarse como la experiencia más traumática de la España del siglo $\mathrm{XX}$, lo que también puede decirse de Alemania con respecto a la Segunda Guerra Mundial. Aunque ambos acontecimientos pueden considerarse ciertamente como incomparables [...] 
sí resulta posible comparar el papel que ha jugado y sigue jugando la memoria histórica del pasado reciente en estos dos países"23.

Hay una interesante literatura sobre la semiótica del único monumento alemán de la posguerra: el "Monumento a los judíos asesinados en Europa", que en cierto modo ha reemplazado a la Puerta de Brandenburgo como símbolo del nuevo Berlín. Las características y la localización de esta instalación monumental ha sido el resultado de un amplio y prolongado debate público. Alguien ha escrito que: "ninguna nación ha llevado a cabo nunca antes el intento de reunificarse en el pedregoso subsuelo del recuerdo de sus crímenes, e instalar el recuerdo de esos crímenes en el centro geográfico de su capital". Habría que decir mejor, sin embargo, que este gesto es símbolo de una ruptura del modelo de unificación y de orgullo nacional de la modernidad. El diseño de la monumental instalación recuerda la imagen de un denso, austero y muy extenso cementerio (cuya superficie es del orden de dos canchas de fútbol), formado por grandes placas mortuorias de cemento clavadas de manera relativamente irregular en el suelo. Pero, "en su negativa radical a la iconografía tradicional del recuerdo, el bosque pétreo de Berlín renuncia a cualquier explicación [...] No hay en la instalación ninguna referencia a quienes hay que conmemorar. Falta cualquier inscripción; inútilmente se buscan los nombres de los asesinados [...] para unos puede ser el cementerio de los sin nombre" 24 , pero es el cementerio de la esencia, o de la humanidad del hombre sin más, aunque el dolor de la memoria que el monumento expresa puede ser también el principio de una nueva humanización. El monumento no tiene una gran altura, ni un frente, o un centro. La experiencia de su significado solamente es posible al internarse y perderse en el frío bosque de cemento.

La identidad política española contemporánea también se ha redefinido a partir del millón de muertos de la guerra civil, de la memoria diferida de las víctimas de la dictadura de Franco, del pacto social y político

${ }^{23}$ Helga Schneider, "Hacer memoria en España y Alemania", en revista Humboldt, München/ Bonn /Saarbrücken, 2005, Año 47, N 143, p. 26.

${ }^{24} \mathrm{Cfr}$. Henrich Wefing, "Monumento al holocausto. Un bloque que la República se ha atado a la pierna para no despegarse del suelo del pasado", en revista Humboldt, núm. cit., p 28. 
de la transición a la democracia y del no retorno al autoritarismo ${ }^{25}$. En estos casos paradigmáticos se muestra especialmente como la experiencia del trauma, que no es puntual o fechable, se diferencia del acontecimiento histórico y aparece temporalmente desplazada, no siempre por una política del olvido sino también porque el propio trauma representa un obstáculo para el recuerdo. La posterior identificación virtual imaginaria, o vicariamente experiencial, es lo que se denomina, para LaCapra, la memoria recuperada; en esta recuperación puede incidir también la tardía trasmisión intergeneracional del trauma, guardado por los sobrevivientes, a veces por años, como algo de lo que no se babla.

En una reciente visita a nuestro país el sociólogo francés Alain Touraine nos decía que él observaba en la Argentina actual un fenómeno comparable a los que acabo de describir. La memoria viva de la tragedia nacional de la dictadura y de los miles de desaparecidos le aparecía a este calificado observador como el rasgo más fuerte y definitorio de nuestra actual identidad política, que ha generado una sensibilidad muy visible y una nueva cultura política centrada en la vindicación de los derechos humanos y de los valores que los fundan.

7.

La formación de esta nueva identidad posnacional, si es que se puede hablar de un acontecimiento de tal envergadura, como estoy proponiendo, se ha desarrollado desde la sociedad civil, a partir de la memoria activa de grupos de mujeres comunes, las madres de los desaparecidos, a las que se fueron sumando luego diferentes organizaciones de los DDHH. Algunos de estos nuevos sujetos sociales miran con justificado recelo la tardía sobreactuación del Estado, a través de la política de derechos humanos del actual gobierno, porque consideran que esta es una lucha de la sociedad civil que reivindica justicia frente al Estado por las violaciones atroces de estos derechos que, en un pasado reciente han sido perpetradas por parte de esta misma institución política, y por otras violaciones que persisten en el

${ }^{25}$ Cfr. también, Reyes Mate, A contraluz de las ideas politicamente correctas, Barcelona Anthropos, 2005, especialmente Cap.1, "Los olvidos de la historia española", y Cap. 2. "Actualidad de las víctimas" (pp. 17-70). 
presente. Pero el significado moral de la reivindicación de los derechos humanos se ha visto devaluado también por el mal uso, o por la política de la memoria que se ha instrumentado desde el gobierno, y que ha cooptado también a algunas de las agrupaciones emblemáticas de la sociedad civil cuyo testimonio de coraje moral durante la dictadura mereció el reconocimiento y la admiración de todo el mundo civilizado.

La rememoración de la gran tragedia Argentina del siglo XX y el compromiso con los valores que hagan efectivo el "nunca más" deberían ser ya sin embargo una convocatoria más abierta y universalizable. Esta nueva oportunidad puede frustrarse si los sujetos de la memoria quedan ligados o circunscriptos a determinadas organizaciones relativamente cerradas, que rivalizan entre sí, y los rituales de la conmemoración quedan reservados de manera excluyente a sacerdotisas que acreditan vínculos de sangre con las víctimas. En la perspectiva histórico-política de la memoria colectiva el Estado y la sociedad en su conjunto tienen que hacerse cargo de la responsabilidad de la tragedia, sin perjuicio de la búsqueda de la verdad histórica y de impulsar ante la Justicia la condena de los culpables por las violaciones contra los derechos humanos.

Esta universalización de la memoria compartida se ve obstaculizada especialmente por la confusión de quienes transformaron su testimonio en defensa de la vida en una identificación con la ideología de las víctimas, en el contexto de lo que La Capra llama una experiencia vicaria. Esta ideología no ha sido por cierto inocente, ha contribuido a la radicalización de la división de la sociedad y a los enfrentamientos que pertenecen al pasado. Aquella ideología de los '70 y los procedimientos de su acción política no contaron con el apoyo de la voluntad popular, y por eso han fracasado en su época y han perdido toda viabilidad en el contexto de las transformaciones del mundo contemporáneo. El proyecto de reactualizarla como alternativa política en el presente lleva inevitablemente a despertar las antiguas divisiones y odios que deberían quedar en el olvido. La memoria de la violencia desatada, del sufrimiento y de las muertes injustas, en cambio, es lo único digno de mantenerse vivo en el presente de aquella experiencia trágica, y lo que puede y debe ser compartido por todos.

En una entrevista televisiva de 1967 se le preguntaba a Jean Paul Sartre porqué usaba el pronombre 'nous' cuando describía el 
colaboracionismo francés con la ocupación nazi y con la deportación de los judíos franceses a los campos de concentración del este europeo. El filósofo aclaró que ése era ante todo un recurso retórico destinado a facilitar la autocrítica y el arrepentimiento. $Y$ si él hubiera identificado a los colaboracionistas como ellos, en oposición al nosotros de los militantes de la resistencia, lo único que hubiera logrado sería la reacción autodefensiva, ideológica y justificatoria de ellos y sus descendientes (lo que LaCapra llamaría la memoria recuperada por la trasmisión intergeneracional del trauma). Pero más allá de un recurso estratégico, el 'nous' tenía para Sartre un significado objetivo, real y más profundo. Porque esas fueron acciones criminales de los franceses " $y$ yo, como Ud. señor periodista, somos franceses". La responsabilidad del genocidio es una responsabilidad colectiva de los alemanes y también de todos los europeos. En política nadie nunca puede decir tajantemente que los culpables son solamente los otros, porque entre ellos y nosotros hay más identidad que diferencia: como seres humanos, como connacionales y como ciudadanos del mismo Estado. Cuando condenamos a los otros, tendemos a considerarnos diferente, decía Sartre, y a marcar la diferencia, pero esto conlleva una actitud aristocrática o elitista. La verdad es que cada uno es como cualquier otro, que pesa más la común identidad y pertenencia a la especie humana, a la misma nacionalidad, y los condicionamientos de la situación histórica, que las diferencias de las cualidades morales, y no sabemos si en situaciones límite, como la tortura y la amenaza de muerte, no seríamos también nosotros capaces de traición o delación y de colaboracionismo con políticas criminales o genocidas. Estas dudas eran compartidas entre los miembros de la resistencia, recuerda Sartre. Si no ponemos el nosotros en un lugar aparte e incorruptible, entonces la memoria de los genocidios podrá ser la memoria de todos. Para ello se requiere todavía la apertura de la otra parte, de las víctimas. Los crímenes de lesa humanidad no son, por cierto, solamente imprescriptibles, sino que son moralmente imperdonables. El cristianismo, decía el ateo Sartre, ha aportado grandes valores a la civilización humana, pero la idea del perdón frente a un crimen aberrante, es un exceso imposible en la experiencia meramente humana. Es inimaginable el perdón y la reconciliación con el victimario en persona. Estas heridas de la memoria solamente pueden ser curadas por el tiempo. $Y$ esta cura habilita para la reconciliación con los descendientes, y con los círculos sociales de origen de los victimarios, en la 
medida en que ellos también hayan tomado distancia de los hechos y se comprometan en la causa común de la justicia, o de la defensa de la vida y los derechos humanos ${ }^{26}$. Hasta aquí las crudas expresiones de Sartre referidas de memoria. La aplicación de estas reflexiones a los problemas de la memoria en la Argentina queda confiada al lector. Pero quiero mencionar por lo menos una interpretación problemática.

Durante la época de Alfonsín y del juicio a las Juntas Militares se construyó la teoría de los dos demonios. Quienes han denunciado esa teoría la acusan de pretender igualar responsabilidades, y sostienen que hubo un sólo demonio responsable del genocidio: el terrorismo de Estado del poder militar. Como alguien ha escrito: ambas posiciones aparentemente tan opuestas, tienen sin embargo algo fundamental en común: la descripción de la existencia de demonios parte del supuesto de que quien hace esta descripción está fuera del círculo demoníaco. No importa que los demonios sean uno o dos, lo que importa es que los sujetos de estos discursos se sitúan en un no lugar, o en un limbo inalcanzable para toda adjudicación de responsabilidad; los demonios son ellos, los otros, los referentes de la enunciación: estrategia para lavar la conciencia de culpa, o dramatización colectiva del subconsciente para disolver nuestros propios fantasmas.

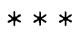

La construcción de una nueva identidad colectiva fuerte y durable en torno a los valores que representan los derechos humanos tiene que pasar por el reconocimiento de que la gran mayoría hemos tenido alguna responsabilidad en lo que nos pasó a los argentinos en la década trágica, por acción, o por omisión, y la gran mayoría de nosotros hemos sido al mismo tiempo, en diferentes formas y grados de sufrimiento, víctimas del régimen

26 En esta situación se manifiesta la relación de complementariedad necesaria, señalada más arriba, entre la investigación histórica y la experiencia, o la memoria, que pueden alcanzar con ayuda de la historia escrita un nivel reflexivo y crítico para la formación del juicio sobre los acontecimientos. Sobre este espinoso tema del olvido y el perdón, cfr. P. Ricoeur, La memoria, la bistoria, el olvido, pp. 539-660. 
de terrorismo de Estado. Este es el vínculo moral y político real y más profundo de la memoria viva que nos une, el vínculo del dolory del miedo.

Quiero cerrar esta exposición con la relectura de algunos versos, reiterados como estribillos del poema "Patria" de Leopoldo Marechal, que yo leía con admiración estética en los años ' 60 , pero ahora los entiendo de manera diferente, como expresión de la memoria viva de su época (y de todas las épocas de nuestra breve historia). Hoy, el mencionado vínculo del dolor y el miedo que nos une cobra una especial intensidad, y aquellos versos pueden leerse como la profecía poética que hace más de medio siglo nos anunciaba esta experiencia trágica y dolorosa que hemos vivido después y que en la actualidad rememoramos como el origen de una nueva identidad política.

La Patria es un dolor que aún no tiene bautismo...

La Patria es un dolor que aún no sabe su nombre...

La Patria es un temor que ha despertado...

La Patria es un amor en el umbral,

Un pimpollo terrible y un miedo que nos busca.

No dormirán los ojos que la miren:

No dormirán ya el sueño pesado de los bueyes...

La Patria no ha de ser para nosotros

Nada más que una hija y un miedo inevitable,

$Y$ un dolor que se lleva en el costado,

Sin palabra ni grito.

Por eso nunca más hablaré de la Patria.

\section{Resumen}

En primer término se muestra fenomenológicamente el papel esencial de la memoria (y del olvido) en la constitución de la identidad (1).Se avanza luego el análisis crítico de los usos de la memoria y de su relación con la historia escrita (2), para introducir en el tema de las políticas de la memoria colectiva (3), y revisar las políticas de identidad del Estado moderno (4). El artículo se refiere en su parte central al hecho de que en los comienzos del Siglo XXI experimentamos que las políticas de la memoria y del olvido del Siglo XIX ya no funcionan con respecto a las nuevas heridas que la memoria viva arrastra del Siglo XX, y la reconciliación 
mediante aquel tipo de elaboraciones no es posible (5). La cuestión seria de la memoria viva no está ligada ya a la historiografía de los acontecimientos fundacionales del estado nación en el pasado remoto, sino que está ligada a otros acontecimientos trágicos de la historia reciente de la sociedad en que vivimos (6). En las sociedades posmodernas se asiste a una redefinición de las identidades políticas tradicionales y a la formación de nuevas identidades posnacionales ligadas a la memoria trágica de los genocidios y al compromiso moral y político del "nunca más"(7).

Palabras clave: memoria, historia, olvido, identidad.

\begin{abstract}
The essential role of memory (and forgetfulness/oblivion) in the constitution of identity is shown first (1). Then, the article moves on to the critical analysis of uses of memory and of its relation with written history (2), to introduce the issue of collective memory policies (3) and go through modern State identity policies (4). In its central part the article refers to the fact that at the beginning of the $21^{\text {st }}$ century we experiment that memory and forgetfulness/oblivion policies do no longer work in respect of the new wounds that live memory drags forth from the $20^{\text {th }}$ century, and reconciliation by means of that kind of elaborations is not possible (5). The serious issue of live memory is no longer bound to the historiography of the founding deeds of the state-nation in the remote past, but is bound instead to other tragic events of the recent history of the society in which we live (6). In postmodern societies we witness a redefinition of traditional identity policies and a formation of new post-national identities bound to the tragic memory of genocides and to the moral and political commitment of "nevermore" (7).
\end{abstract}

Key words: memory, history, forgetfulness, identity. 